\title{
Standardized Payment Procedures as Key Enabling Factor for Mobile Commerce
}

by

Nina Kreyer, Key Pousttchi ${ }^{1}$, Klaus Turowski ${ }^{1}$

June 2002

in: Bauknecht, K., Tjoa, A. M., Quirchmayr, G., ed., EC-Web 2002, Springer Lecture Notes in Computer Science, Aix-en-Provence, (France), September 2002, 2455. volume, Springer, Berlin, 2002, p.400-409

${ }^{1}$ chair for business administration, particularly business informatics, University of Augsburg 


\title{
Standardized Payment Procedures as Key Enabling Factor for Mobile Commerce
}

\author{
Nina Kreyer ${ }^{1}$, Key Pousttchi ${ }^{2}$, Klaus Turowski ${ }^{2}$ \\ ${ }^{1}$ University of Augsburg, Chair of Business Information Systems (Wirtschaftsinformatik I), \\ Universitaetsstrasse 16, 86135 Augsburg, Germany, phone: +49 (821) 598-4138, fax: -4225, e- \\ mail: nina.kreyer@wiwi.uni-augsburg.de \\ ${ }^{2}$ University of Augsburg, Chair of Business Information Systems (Wirtschaftsinformatik II), \\ Universitaetsstrasse 16, 86135 Augsburg, Germany, phone: +49 (821) 598-4431, fax: -4432, e- \\ mail: \{key.pousttchi, klaus.turowski\}@wiwi.uni-augsburg.de
}

\begin{abstract}
Companies are not going to invest into the development of innovative applications or services unless these can be charged for appropriately. Thus, the existence of standardized and widely accepted mobile payment procedures is crucial for successful business-to-customer mobile commerce. In this paper we reflect on the acceptance of mobile payment and examine the characteristics of current mobile payment procedures. The outcomes of the paper are a categorization of current mobile payment procedures with strategic, participation and operational criteria and, based on these results, the derivation of the five mobile payment standard types prepaid, mobile money, conventional settlement, premium rate number and dual-card. Finally, a prospect is given to possible further development of mobile payment procedures in the direction of an integrative universal mobile payment system (UMPS).
\end{abstract}

\section{Introduction}

The ever growing number of mobile phone users as target group represents an enormous potential for mobile commerce (MC) as a new level of electronic commerce (EC). So far, mobile applications are mostly still the transformation of conventional Internet applications or EC business models on mbile devices. But in order to be successful (and thus gain profits) in a MC setting, this is not sufficient. Added values are necessary.

For purposes of this paper, we define EC as any kind of business transaction, in the course of which transaction partners employ electronic means of communication, may it be for initiation, arrangement or realization of performance (cf. [2]). We define MC as a subset of these, on condition that at least one side uses mobile communication techniques.

Typical mobile added values originate from ubiquity, context-sensitivity, identifying functions or command and control functions of MC applications (cf. [10] and the extension introduced in [17]). To realize their potential, a new technical infrastructure is needed, e.g. allowing "always-on" functionality through packageoriented data transmission. While the forthcoming availability of GPRS (Generalized Packet Radio Service) and UMTS (Universal Mobile Telecommunications System) in 
Europe will solve this shortcoming, another major problem still remains unsolved: the availability of adequate payment procedures. Since companies are not going to invest into the development of innovative applications or services unless these can be charged for appropriately, the existence of standardized and widely accepted mobile payment (MP) procedures is crucial.

This is especially true for business-to-customer (B2C) MC, for which reason we focus on B2C MP in this paper. The customer-to-customer $(\mathrm{C} 2 \mathrm{C})$ variant itself may perhaps not be a good deal for the payment provider. But as it provides an added value for the customer and thus, an incentive for usage and spreading of a MP procedure, $\mathrm{C} 2 \mathrm{C} \mathrm{MP}$ is to be examined along with B2C MP. For special target groups, $\mathrm{C} 2 \mathrm{C}$ MP could be the main reason to use a MP procedure, e.g. for young people with high affinity to technology, but without own income.

We define MP as a subset of MC, which deals with the completion of pay ment. We focus therein not on technical issues or the clearing process, but on the payment interface to the customer. As is shown later, MP is crucial for, but not limited to MC scenarios. On the contrary, usability of a MP procedure in scenarios other than MC is relevant for its acceptance.

After a reflection on the issue of acceptance, characteris tics of MP procedures are identified, classified and MP standard types are derived. Based on these results, major shortcomings of existing solutions are explained and opportunities for their improvement are shown.

Whenever we talk in this paper about a general payment method such as credit card usage, electronic payment or MP, we refer to the term payment systems. Whenever we talk about concrete solutions such as Paybox, Paysafecard or Sonera Mobile Pay, we refer to the term payment procedures.

\section{Acceptance of MP}

\subsection{General acceptance}

The examination of the development of payment procedures in the past shows that the key to acceptance is in the hands of customers (cf. [9], [16]).

In the course of a study on mobile banking, Speedfacts Online Research interviewed about 16.500 Internet users about their payment preferences if away. On the issue of general acceptance, about two third stated that they will surely or can imagine paying with their mobile phone; more than half stated that they will surely or can imagine making money transfers with their mobile phone. The most significant acceptance was ascertained with persons already using electronic banking (cf. [19]). On the issue of the preferred payment method if away, the mobile phone would already be preferred by about a quarter of the interviewees for micropayments (less than $2.50 €$ ), a third for macropayments from $2.50 €$ up to $50 €$, a fifth for macropayments from $50 €$ up to $250 €$ and anyhow by $13 \%$ for amounts over $250 €$. In the segment between $12.50 €$ and $50 €$ paying by mobile phone would be the most preferred method.

These numbers cannot implicitly be extrapolated on the whole target group of 
mobile device users, because the average Internet user may tend to show more affinity to technology than the average user of a mobile device (who often just uses phone functionality). Nevertheless it can be concluded a tendency showing that general preconditions for an acceptance of MP by the customer are good. But the decisive factor for a market breakthrough is the acceptance and actual usage of concrete MP procedures.

This consideration allows us to identify a major failure risk in the transformation of general MP acceptance into this concrete acceptance and usage.

\subsection{Acceptance of individual payment procedures}

If, as we concluded in chapter 2.1, the key is in the hands of customers and a general acceptance of MP can be stated at least in a significant part of the target group, this leads us to the question on determinants influencing the acceptance of a single MP procedure by the customer. Furthermore, other participants (above all, merchants) will only be able to follow customer preferences up to a defined point, where disadvantages overweigh significantly the advantages.

It is already much said about this issue of acceptance (cf. e.g. [18], [8], [1]). In our point of view most of the arguments can be subsumed to the categories

- cost (which includes direct transaction cost and fixed cost of usage as well as cost for technical infrastructure on the part of the customer, e.g. a new mobile phone perhaps necessary, and the merchant, e.g. the integration of the payment solution in his existing IT infrastructure),

- security (which includes not only integrity, authorization, authentication, confidentiality and non-repudiation of transactions, but also the issue of subjective security from the vie wpoint of the customer),

- convenience (which includes e.g. ease and comfort of use as well as the attainment of concrete benefits through the use).

For the latter, it is important that a procedure is not limited to MC scenarios, but can be used in as many as possible other settings, too. Briefly: It should be possible to use the procedure whenever, wherever and for whatever kind of payment the user wants to.

\subsection{Relevant M-Payment scenarios}

Brokat calls the different payment settings "r-world", "e-world" and "m-world" (cf. [8]). We will distinguish them a little more precisely and, for the reasons mentioned in chapter 1 , add the $\mathrm{C} 2 \mathrm{C}$ scenario. 
This leads us to four general scenarios for the usage of MP: the mobile commerce scenario, the electronic commerce scenario, the stationary merchant scenario and the customer-to-customer scenario (cf. table 1). We also note that in different settings MP also is competing to different other payment systems. In this connection, we already treated a comparison with competing systems for the stationary merchant scenario in chapter 2.1 and furthermore noted the high influence of the amount level on this competition.

Table 1. Relevant MP scenarios

\begin{tabular}{|l|l|l|}
\hline Scenario & Description/Example & $\begin{array}{l}\text { Competing } \\
\text { payment }\end{array}$ \\
\hline $\begin{array}{l}\text { mobile } \\
\text { sommerce } \\
\text { scenario }\end{array}$ & $\begin{array}{l}\text { new applications and services, e.g. context-sensitive } \\
\text { information }\end{array}$ & - - - \\
\hline $\begin{array}{l}\text { electronic } \\
\text { commerce } \\
\text { scenario }\end{array}$ & $\begin{array}{l}\text { all kinds of B2C EC excluding MC, e.g. purchase of } \\
\text { goods or content via the Internet }\end{array}$ & $\begin{array}{l}\text { offline } \\
\text { debit-/credit card } \\
\text { e-payment }\end{array}$ \\
\hline $\begin{array}{l}\text { stationary } \\
\text { merchant } \\
\text { scenario }\end{array}$ & $\begin{array}{l}\text { slassical "face-to-face" commerce, e.g. purchase in a } \\
\text { supermarket, usage of a ticket machine, taxi }\end{array}$ & $\begin{array}{l}\text { cash } \\
\text { debit-/credit card }\end{array}$ \\
\hline $\begin{array}{l}\text { customer-to- } \\
\text { customer } \\
\text { scenario }\end{array}$ & $\begin{array}{l}\text { money transfers between individuals, e.g. pocket- } \\
\text { money for children, settling debts for small amounts }\end{array}$ & $\begin{array}{l}\text { (cash) } \\
\text { offline) }\end{array}$ \\
\hline
\end{tabular}

The distinction of these scenarios is not only important for the examination of different payment procedures and the derivation of standard types in chapters 3 and 4, but also for a strategy of market entry and its conclusions on the construction of payment procedures. For a brief look on these issues, cf. [9].

We claimed in chapter 1, that MP is thus crucial for, but not limited to MC scenarios. We will see later, that in any payment scenario there is at least some MP procedure that makes sense and that there are several MP procedures usable in more than one payment scenario.

Before we use these payment scenarios, it is useful to give a short reflection on the relevance of the usability in each of the payment scenarios for the diffusion process of the procedure.

- Mobile commerce scenario. As we stated above, MP allows unfolding MC's potential. But as MC itself represents only low revenue rates up to now, it is questionable if customers accept a MP procedure just to possibly use $\mathbf{i}$ sometimes in a MC setting. The dilemma could arise that nobody uses a MP procedure because it is limited to MC and nobody uses MC because there is no widely accepted MP procedure.

- Electronic commerce scenario. In opposite to MC, EC already represents a good revenue potential today. But the payment problem remains still unsolved and most transactions are paid through offline methods such as money transfer after delivery, debit procedures or credit card (cf. e.g. [18], 
[23]), with obvious disadvantages. On the other hand, we saw that the acceptance potential for MP among Internet users is already high (cf. chapter 2.1) and that this target group could be very interesting for MC.

- $\quad$ Stationary merchant scenario. As we illustrated in chapter 2.1, there also is a good acceptance potential for MP as new mean of payment in this scenario, especially for low to medium macropayments $(2.50 €$ to $50 €)$. The revenue potential is definitely the highest of the four scenarios. But it remains uncertain not only if the average mobile phone user is the right target group for a pioneer application like MP, but also if it will be possible to convince traditional merchants of a payment procedure without a significant number of people already using it, thus, demanding him to accept it.

- Customer-to-customer scenario. The opportunity to transfer money from customer to customer represents mostly an incentive for usage and spreading of a MP procedure. Although for special target groups, C2C MP may be the main reason to use a MP procedure; this is unlikely for the average user (cf. chapter 1).

\section{Typical Characteristics of MP Procedures}

In order to distinguish different types of MP solutions - and thus unambiguously identify any given payment procedure - the characterization of significant diffe rences in MP systems is crucial. Besides analyzing if a MP procedure works within a certain payment scenario (cf. chapter 2.3) it is also necessary to decide whether it can be used to cost-efficiently settle micro-, macro- or picopayments (cf. [6], [22]). Since within most MP procedures a variety of different stakeholders, such as merchants, telecommunication providers (telcos), banks or financial service providers (e.g. credit card companies), specialized intermediaries and old economy companies are joined, their roles and objectives have to be analyzed. Telcos may e.g. operate the technical infrastructure and be involved in the payment process as well, e.g. when they offer billing services or operate a MP procedure (cf. [20]). Since the customer will finally decide about the establishment of payment procedures (cf. chapter 2.1, [9], [16]), customer specific topics, such as the need for a pre-registration or the technology required to use a MP procedure, have to be examined. While most current MP procedures are based on simple message exchange via short-messaging-services (SMS) or the wireless application protocol (WAP), some MP procedures require dualslot or dual -chip-phones. Some MP procedures even require the installation of special software tools, e.g. to create digital coins. The MP procedures themselves are either token or account-based. Within token-based procedures virtual cash, representing (fractions of) "real" money, is exchanged whereas account-based procedures settle payments via the customers settlement-account. The payments are either deducted via prepaid, instant-paid or post-paid methods and may be settled via various payment methods such as prepaid-cards, digital wallets, direct debiting, offline payments, credit cards or phone bills. For a more detailed analysis of the instances mentioned above cf. [9]. According to these results the main characteristics 
of MP procedures and their instances can be combined. In table 2 we do this following the morphological method (cf. [24]).

Table 2. Morphological box of MP characteristics and instances

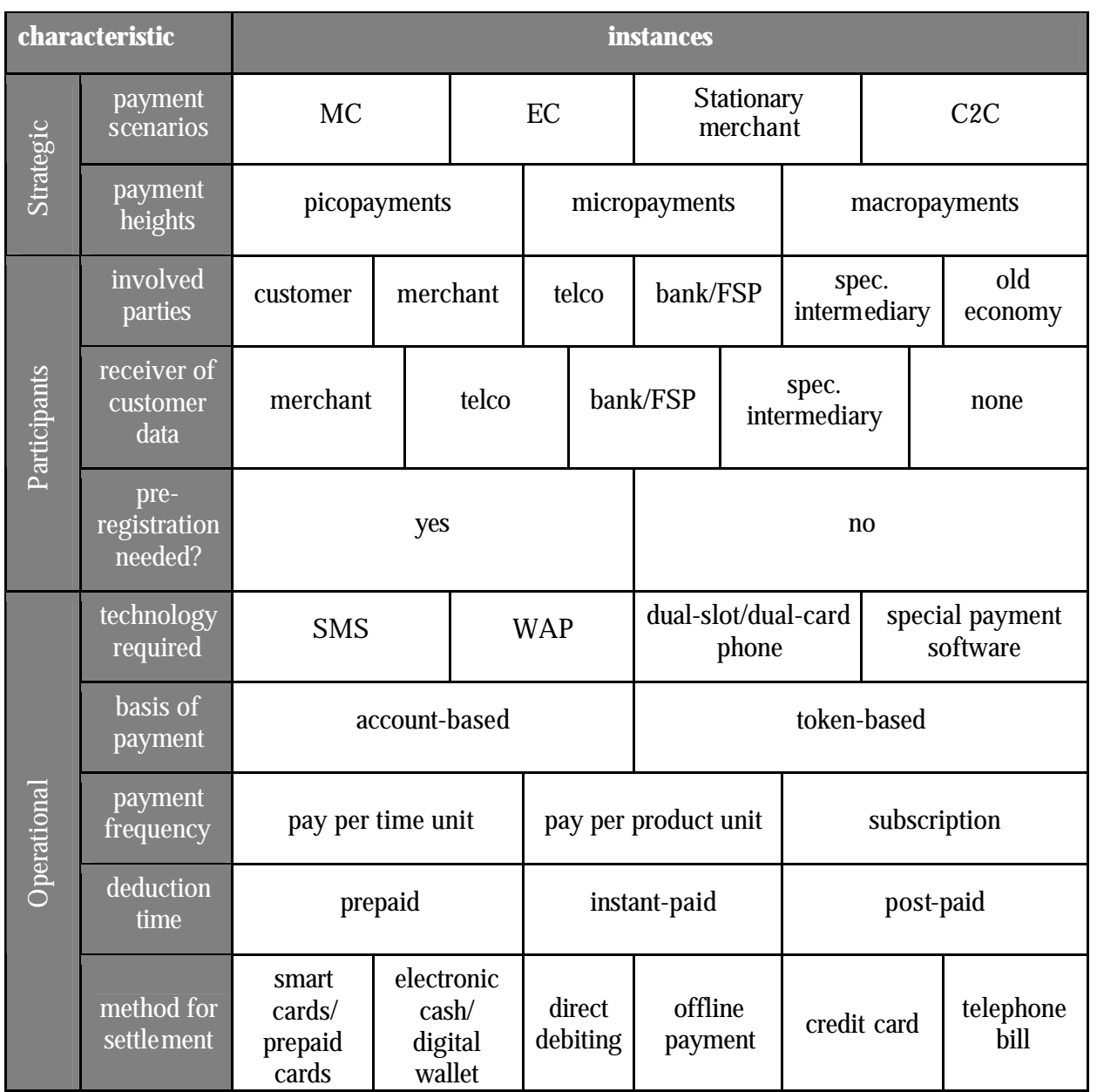

\section{Derivation of MP Standard Types}

\subsection{General remarks}

As we have shown in chapter 3, a broad variety of characteristics is necessary to classify a MP procedure. The examination of current MP procedures (cf. e.g. [6], [9]) shows that neither these and their properties are evenly distributed within the scheme, nor typical patterns are existing which are valid over all of the relevant characteristics. Therefore, we cannot decompose the box in clusters and have to state the absence of 
accurately definable disjoint types. Anyhow, we can identify single instances of the shown characteristics as respectively constituent for a significant group of MP procedures. These groups prepaid, mobile money, premium rate number, conventional settlement and dual-card represent different concepts, but are not totally disjoint. Any of the current MP procedures can be ranked in (at least) one of the groups. We term these groups as standard types of MP procedures or MP standard types.

\subsection{The Prepaid Standard Type}

The prepaid standard type is defined by the instance prepaid of the characteristic deduction time.

Typical use are micro- and lower macropayments in the EC and MC scenario. Prepaid procedures are either based on pre-registration and a rechargeable account or on a prepaid card which contains a code number and is bought in a store. Up to now, the latter is the only possibility to realize the instance none for receiver of customer data, thus, to realize anonymous payment.

Because of the inherent budget restriction and prove of solvency, prepaid procedures are particularly suitable for minors or young people without own income.

So far, no prepaid-card system has evolved within MC payment procedures However, this seems to be a question of marketing because the use of these procedures is principally already possible. A reason may be the low revenue rates in the MC scenario up to now.

Samples for the prepaid standard type are Paysafecard (cf. [15]), MicroMoney (cf. [11]) and Mobilix (cf. [12]).

\subsection{The Mobile Money Standard Type}

The mobile money standard type is defined by the instance token-based of the characteristic basis of payment.

This type, using digital coins or wallets, can be considered as a subtype of prepaid procedures, but represents an own weighty concept and principally can exist outside of this superordinate group (and perhaps will do so for future MP procedures). For this reason, we adequate it with the other groups as a separate standard type.

After various attempts to place token-based electronic payment procedures have failed (such as eCash supported by Deutsche Bank in Germany), the development in this domain has slowed down. Up to now, no MP procedure of this standard type is in use.

For future applications, mobile money could be especially interesting for the stationary merchant scenario, where payment with digital coins from a mobile device could e.g. be carried out via Bluetooth at the point of sale in a store, at a vending machine or in a taxi.

A sample for the mobile money standard type is FairCash (cf. [7]), which is still in a development state.

\subsection{The Premium Rate Number Standard Type}

The premium rate number standard type is defined by the instance telephone bill of the characteristic method for settlement.

This type covers the call of premium rate numbers for obtaining a code via voice 
interface as well as premium rate SMS and the settlement of specially labeled data packets for value added services.

The type is characterized through the dominant role of the telecommunication provider. A settlement over the already existing billing relationship is especially interesting for the MC scenario. While this is univocally true for value added services, it can be problematic for other services or for physical goods, since in a number of countries legal restrictions prohibit the settlement of services others than telecommunication-related ones via the telephone bill (requirement of a bank license).

For mobile phone subscribers using prepaid cards, the premium rate number type coincidences with the prepaid type.

The premium rate number standard type is carried out by nearly any telecommunication provider. A particular sample for a MP procedure based on this is Sonera Mobile Pay (cf. [6], [3]), an interesting example for the settlement of value added services provides i-mode (cf. [5], [3]).

\subsection{The Conventional Settlement Standard Type}

The conventional settlement standard type is defined by the instance direct debiting and/or credit card of the characteristic method for settlement.

This type covers any procedure which is just using an interface on a mobile device to access a conventional mean of payment such as direct debiting or credit card. The interface can be based either on voice or on a data transmission solution.

The type is characterized through the dominant role of a specialized intermediary. But since it is based on conventional settlement, it is in truth bank/FSP-centered. Thus, the relations between the specialized intermediaries and the banks/FSP merit closer examination in the future.

Samples for the conventional settlement standard type are Paybox (cf. [13], [4]), the former Payitmobile (cf. [6]), Street Cash (cf. [21]) and PayPal (cf. [14]).

\subsection{The Dual-Card Standard Type}

The dual-card standard type is defined by the instance dual-slot/dual-card phone of the characteristic technology required.

This type, using either dual-slot or dual-SIM technology for security or other issues, can presently be considered as a subtype of conventional settlement procedures. But like the mobile money standard type in chapter 4.3 , it represents an own weighty concept and principally can exist out of conventional settlement, wherefore we adequate it with the other groups as a separate standard type.

In addition to using the chip of the user's standard credit card to carry out a MP procedure with a dual-slot phone, another particularly interesting concept could be the use of dual-card in combination with digital coins and conventional settlement, which could potentially allow for an innovative procedure to generate digital coins on a mobile device for instantaneous disposal, where the generation of the coin uses an online debit procedure with the customer's bank.

Dual-card/dual-slot solutions are playing also an important role in current developments in the field of mobile banking (especially for mobile signatures).

Present samples for the dual-card standard type are Iti Achat and EMPS (cf. [3]). 


\section{Conclusions and perspectives}

In this paper we reflected on the acceptance of MP and examined the characteristics of current MP procedures.

As the outcome of the paper we presented a scheme with strategic, participation and operational criteria which allows us to unambiguously identify and characterize any given MP procedure and, based on these results, introduced the MP standard types prepaid, mobile money, premium rate number, conventional settlement and dual-card.

In chapter 2.1, we characterized the starting conditions for MP as good and identified the decisive point in the transformation of this general interest of users into their everyday usage of concrete MP procedures.

We did not find an "ideal" procedure type who fits all needs and do not believe that we will see one in the future. A possible solution, however, would be MP procedures which aggregate two or more of the standard types, making it possible for the customer to use their advantages without giving up too much convenience. On the other hand, widely accepted standardization in the field of MP procedures' interfaces would be hard to accomplish and is not in sight.

A more global approach could be the development of an integrative universal mobile payment system (UMPS) based on an abstraction layer above the procedure level. This UMPS would have to be user-centered and allow to use any given payment procedure on any given mobile device and network with any given merchant and financial service provider interface.

A respective solution would allow maintaining the variety of existing MP procedures and the variety of mobile devices. At the same time, customers as well as merchants could be relieved of the need to occupy themselves with the payment problem for mobile solutions.

\section{References}

[1] Cheong, Y.C.; Tan, C.-L.: Payments in Mobile Commerce. Singapore, 2001

[2] ECOM: Electronic Commerce - An Introduction. Source: http://ecom.fov .uni-mb.si/center/ [1998, 05-15].

[3] EPSO: ePSO Inventory DataBase. Source: www.jrc.es/cfapp/invent/list.cfm [2002, 06-05].

[4] Henkel, J.: Mobile Payment. In: Silberer, G.; Wohlfahrt, J.; Wilhelm, T. (Hrsg.): Mobile Commerce. Wiesbaden, 2002.

[5] I-mode: Information available at: http://www.nttdocomo.com [2002, 0601].

[6] Kieser, M.: Mobile Payment - Vergleich elektronischer Zahlungssysteme. In: Meier, A.: Mobile Commerce. Heidelberg, 2001.

[7] Kreft, H.: The FairCash System. München, 2002. 
[8] Kruppa, S.: Mobile Payment. Beyond the M-Commerce Hype. Stuttgart, 2002.

[9] Kreyer, N.; Pousttchi, K.; Turowski, K: Characteristics of Mobile Payment Procedures. In: Proceedings of the ISMIS 2002 Workshop on M-Services, Lyon 2002.

[10] Kuhlen, R.: Informationsmarkt: Chancen und Risiken der Kommerzialisierung von Wissen. 2. Aufl., Konstanz, 1996.

[11] MicroMoney: Information available at: www.detecardservice.de/de /micromoney [2002, 06-01].

[12] Mobilix: Information available at: www.pbs.dk/english/nyheder/nyheder /mobilixpress.htm [2002, 06-01].

[13] Paybox.net AG: Information available at: www.paybox.de [2002, 02-12].

[14] PayPal: Information available at: www.paypal.com [2002, 02-14].

[15] Paysafecard: Information available at: www.paysafecard.de [2002, 02-12].

[16] Pousttchi, K.; Selk, B.; Turowski, K.: Akzeptanzkriterien für mobile Bezahlverfahren. In: Tagungsband zur MKWI 2002 Teilkonferenz Mobile und Collaborative Business, Nürnberg, 2002.

[17] Pousttchi, K.; Selk, B.; Turowski, K.: Enabling Mobile Commerce through Mass Customization. Augsburg, 2002.

[18] Robben, M.: ePayment: Alte Besen kehren wch am besten. Available: http://ecin.de/zahlungssysteme/epayment, 2001.

[19] Speedfacts Online Research GmbH: mBanking - The Future of Personal Financial Transaction? Frankfurt, 2001.

[20] Stone, A.: Working Towards Universal Payment Solutions. Available: www.mcommercetimes.de [2002, 02-22].

[21] Street Cash. Information available at: www.streetcash.de [2002, 02-14].

[22] Sutherland, E.: Minipayments Start Adding Up for Carriers. Available: www.mcommercetimes.de [2001, 12-04].

[23] Wiegmann, D.: Vielfalt an Bezahlsystemen bremst E-Commerce. dpa 2002, 03-07.

[24] Zwicky, F.: Entdecken, Erfinden, Forschen im Morphologischen Weltbild. München, 1966.

\section{Keywords:}

Mobile payment, electronic payment, mobile commerce, mobile added values, universal mobile payment system, UMPS 